\title{
Salvador Mohor Abuauad* \\ El Recurso de Protección y los derechos sociales: Una deuda pendiente
}

\section{Algunas reflexiones básicas}

El propósito de esta presentación es demostrar que la marginación de los derechos sociales, económicos y culturales (derechos de la segunda generación) del ámbito de acción del recurso de protección (RP), es errada, pues descansa sobre una verdad a medias, y arbitraria, ya que carece de un fundamento de razón, justicia o bien común que la justifique suficientemente. Por consiguiente, se concluye en la necesidad de modificar el artículo $20^{\circ}$ de la Constitución vigente, con miras a asegurar su directa protección y terminar así, definitivamente, con la inconstitucional práctica de la "propietarización”, surgida del ingenio de nuestros abogados y mantenida por la tolerancia de los Tribunales, frente a la necesidad de llenar un vacío de nuestra institucionalidad que ya no puede mantenerse por más tiempo.

1. Los derechos sociales, económicos y culturales son una característica esencial del llamado Estado social de Derecho y representan un paso más en el desarrollo de nuestra conciencia moral y jurídica, en cuanto amplían las fronteras de la solidaridad social y propenden a una más justa distribución de los ingresos.

2. Sabemos que, aun cuando sus orígenes se sitúan en el siglo XIX, especialmente a partir de la revolución de 1848, en Francia, los derechos sociales responden a una tendencia que se desarrolla con relativa fuerza en los primeros años del siglo XX, principalmente con posterioridad al término de la primera gran guerra, y que se incorporan al ámbito de las políticas públicas y al texto de las Constituciones, buscando de manera progresiva y sostenida su reconocimiento institucional. Con ellos se

* Profesor Titular de Derecho Constitucional, Universidad de Chile. busca mejorar y fortalecer la condición socio-económica de las personas frente a los riesgos y contingencias de la vida, mediante prestaciones económicas o de servicio, sea que estas provengan directamente del Estado o de organismos que operan bajo su control, o bien, del propio sector empleador, especialmente al fragor de la presión sindical y la negociación colectiva. 
Al tímido reconocimiento constitucional de la primera época (Constituciones Alemana (1919), de Austria (1920) y México (1917) principalmente), se sigue un movimiento más amplio favorable a su institucionalización en las democracias occidentales (Constituciones Española de 1931, Irlandesa de 1937, Italiana de 1946, Española de 1978, Portuguesa de 1976 y, más débilmente, la Constitución de Dinamarca de 1953)1 y que remata en la aprobación por la Asamblea General de las Naciones Unidas del Pacto Internacional de Derechos Económicos, Sociales y Culturales (1966), y en la aprobación de los Principios de Limburg (1987) y las directrices de Maastricht (1997).

3. Aún cuando todos los derechos sociales en último término buscan satisfacerse con prestaciones económicas o de servicio, se suele distinguir no obstante entre derechos sociales prestacionales y derechos sociales no prestacionales. Se da el nombre de prestacionales a aquellos derechos sociales que se satisfacen directamente con prestaciones económicas o de servicio que provienen del Estado o entidades privadas que actúan legalmente bajo el control del Estado, tales como Isapres, AFP y colegios particulares subvencionados. Es, por ejemplo, el caso de los derechos a la protección de la salud, a la seguridad social, a la educación y, en parte, el derecho a vivir en ambiente libre de contaminación. Los no prestacionales, en cambio, son aquellos cuyo ejercicio permite a sus titulares -generalmente actuando colectivamente- procurarse mejores condiciones de vida, de trabajo y remuneración, tales como los derechos a la sindicalización, la huelga, o negociación colectiva. Como podrá apreciarse, estos derechos son, en realidad, el medio a través del cual sus titulares obtienen las prestaciones económicas o de servicio para el mejoramiento de su condición social, con lo cual, en definitiva, puede afirmarse que todos los derechos sociales propenden al mismo fin, directa o indirectamente.

4. Debido a que la satisfacción por el Estado de los derechos sociales prestacionales queda subordinada a los recursos económicos de que aquél disponga, de tal manera que frente a la carencia o insuficiencia de tales recursos, se suele argumentar que nada se obtendría, desde un punto de vista práctico, con accionar en su contra, es que se ha concluido que tales derechos en general no son susceptibles de exigirse por vía judicial, pues su indeterminación alentaría exigencias cuyos alcances, en los hechos, solo tendrían como límite el cielo. En el contexto de estas ideas, la Constitución de 1980, a nuestro juicio indiscriminadamente, como luego se explicará, marginó del ámbito de acción del Recurso de Protección a los derechos sociales (art. 20), y la CENC, ilustrando los inconvenientes de una eventual judialización, aludía a los casos hipotéticos de quienes demandan al Estado para exigir la construcción de escuelas o de hospitales, para obtener una plaza de trabajo, o para que se descontamine el planeta. En principio los fundamentos de la marginación parecen razonables, puesto que las

1 En esta perspectiva resulta sin embargo interesante el artículo 75 , inciso $2^{\circ}$, de la Constitución de Dinamarca, por la riqueza de su contenido social: "Quienquiera que no esté en condiciones de proveer a su subsistencia y a la de los suyos, y cuyo mantenimiento no esté a cargo de otras personas, tendrá derecho a la asistencia de las autoridades, a condición, sin embargo, de someterse a las obligaciones establecidas por la ley en este punto". 
políticas y programas destinados a mejorar la condición material de las personas, con miras a garantizar la igualdad de oportunidades, deben llevarse a cabo siempre en la medida de los recursos de que disponga el Estado. Nadie, en efecto, podría pretender que el subdesarrollo socio-económico de un país se arregla demandando al Estado ante los tribunales. La Convención Americana de los Derechos humanos y el Pacto Internacional de derechos económicos, sociales y culturales parecen servir de fundamento a esta apreciación, en cuanto condicionan la acción social del Estado a los recursos disponibles. ${ }^{2}$

5. Por la razón señalada precedentemente la Constitución de 1980, antes de la reforma de 2005, si bien admitía la procedencia del Recurso de Protección para el amparo del derecho a vivir en ambiente libre de comunicación, respecto de acciones ilegales y arbitrarias que generan contaminación, la desestimaba respecto de las omisiones que generan contaminación, entre otras razones, porque cuando el Estado no realiza prestaciones ambientales de conservación, reparación o mejoramiento, se encuentra en estado de omisión, y obligarlo a salir de ella, vía recurso de protección, implicaba el riesgo de sobrepasar eventualmente sus capacidades económicas, en la lógica de las consideraciones ya reseñadas.

6. Sin embargo, lo referido en los puntos que preceden, en cuanto a la improcedencia del recurso de protección respecto de los derechos sociales, es sólo pertinente respecto de los derechos sociales prestacionales, cuando su consagración o reconocimiento Constitucional no está complementado por normas legales que determinen o especifiquen la prestación económica o de servicio, tanto desde el punto de vista cualitativo como cuantitativo. Por consiguiente, cuando se ha establecido legalmente en qué consiste concretamente la prestación, cuál habrá de ser su monto, los requisitos para obtenerla o realizarla y consecuentemente se haya hecho la correspondiente provisión presupuestaria, la objeción de indeterminación se hace improcedente. Por lo tanto la intermediación legal es indispensable que exista para evitar que los derechos sociales se transformen en meras declaraciones nominales. De no ser así, a lo más, sólo servirían de base para la formulación de políticas públicas a través de las cuales el Estado de modo general, y en la medida de sus recursos, propendería al mejoramiento de la condición social de las personas mediante prestaciones que éstas no estarían en situación de reclamar judicialmente, pues no se pueden respetar, proteger o satisfacer jurídicamente derechos cuya cualificación y cuantificación son

2 Artículo $2^{\circ}$ del Pacto Internacional de Derechos Económicos Sociales: Cada uno de los Estados Partes en el presente Pacto se compromete a adoptar medidas, tanto por separado como mediante la asistencia y cooperación internacionales, especialmente económicas y técnicas, hasta el máximo de los recursos de que disponga, para lograr progresivamente, por todos los medios apropiados, inclusive en particular la adopción de medidas legislativas, la plena efectividad de los derechos aquí reconocidos.

Artículo 26 de la Convención Americana sobre Derechos Humanos: Los Estados Partes se comprometen a adoptar providencias, tanto a nivel interno como mediante la cooperación internacional, especialmente económica y técnica, para lograr progresivamente la plena efectividad de los derechos que se derivan de las normas económicas, sociales y sobre educación, ciencia y cultura, contenidas en la Carta de la Organización de los Estados Americanos, reformada por el Protocolo de Buenos Aires, en la medida de los recursos disponibles, por vía legislativa u otros medios apropiados. 
desconocidas. Recurriendo al subterfugio de la propietarización de los derechos sociales, se ha logrado, en ciertos casos, su satisfacción indirecta por la vía del recurso de protección, aunque a nuestro juicio, con evidente infracción del artículo 20 de la Constitución, que enumera de modo taxativo los derechos amparables por esta vía. Con este subterfugio, en efecto, carecería de todo sentido esa enumeración y habría bastado con que el referido artículo se refiriera sólo a la protección del derecho de propiedad. Pero aun este subterfugio solo se hace posible si el derecho social que se reclama indirectamente se encuentra previamente determinarlo por la ley, pues no se puede ser dueño de bienes u objetos indeterminados o indeterminables.

7. Ahora bien, si no obtente la intermediación legal, el Estado se abstuviera de dar satisfacción a los derechos sociales omitiendo total o parcialmente la prestación correspondiente, incurriría inevitablemente en una omisión ilegal, y esa omisión sería ahora susceptible de reclamación judicial, sin que fuera ya procedente formular la objeción de indeterminación que doctrinariamente se suele esgrimir para obviar la judicialización, puesto que ahora, la obligación del Estado se encontraría acotada cualitativa y cuantitativamente, y su cumplimiento se haría perfectamente exigible. Tampoco sería ordinariamente aceptable la objeción basada en la ausencia de recursos económicos suficientes, puesto que si la ley ha fijado de antemano la cuantía de los beneficios que habrían de asignarse para la satisfacción de los derechos económicos, sociales y culturales, entonces el gasto correspondiente también habrá debido contemplarse oportunamente en el presupuesto de la nación o en el del órgano o entidad que jurídicamente corresponda. Situaciones extremas de crisis financiera en que periódicamente se sumen los Estados (por ejemplo Grecia y España a partir de la crisis europea del 2008), no afectarían en esencia la judicialización, pero por la fuerza de los hechos terminarían provocando eventualmente una disminución proporcional, o en el peor de los casos, una suspensión temporal de los beneficios. ${ }^{3}$ Ello exigiría una readecuación de la legislación vigente, en orden a reducir a menores términos la determinación cualitativa y cuantitativa preexistente, en el marco de un descontento social que, a la larga, impulsaría hacia el restablecimiento de la normalidad deseada.

8. Por lo ya referido en cuanto a la intermediación legal, es que el constituyente de 2005 no ha tenido inconveniente en extender el ámbito de aplicación del recurso de protección a las omisiones que generan contaminación, con tal que se demuestre su ilegalidad. En efecto, hoy el artículo 20 reformado dispone que el RP, en el caso del $\mathrm{N}^{\circ} 8$ del artículo 19 , procederá cuando el derecho medio ambiental "sea afectado por un acto u omisión ilegal ". Razonablemente, en la reforma, no se hace referencia a la opción de arbitrariedad como condición de procedencia del recurso, pues esta opción no descansa necesariamente en la infracción de una norma legal y, eventualmente, nos retraería a una situación de ausencia de intermediación legal, que precisamente

3 De acuerdo a los Principios de Limburg, de 1987, y a las Directrices de Maastricht de 1997, que especifican los criterios bajo los cuales se infringen los derechos del Pacto Internacional de los Derechos Económicos Sociales y culturales, no hay infracción cuando la razón que lleva al Estado a desatender tales derechos es la falta de recursos suficientes y disponibles (p. 72 y D. 14, respectivamente). 
es la objeción que se esgrimía para negar lugar a la judicialización de los derechos sociales. Lo anterior no significa, por supuesto, que la arbitrariedad de una omisión no pueda voluntariamente reclamarse por vía judicial, pero solo con un carácter complementario de la ilegalidad.

9. Pues bien, podemos preguntarnos, sobre la base de las consideraciones referidas y, especialmente, teniendo en vista el criterio interpretativo que fluye de la reforma de 2005 al art. 20 de la Constitución, ¿Por qué si respecto de un derecho parcialmente social, como el derecho a vivir en un ambiente libre de contaminación, se ha hecho expresamente procedente el RP para reclamar prestaciones ilegalmente omitidas por el Estado, no se hace aplicable también el mismo criterio interpretativo para fundar la procedencia del RP, respecto de los demás derechos sociales prestacionales afectados por omisiones ilegales, y terminar de una vez con el subterfugio de la propietarización de los derechos?

En esta línea de pensamiento se sugiere como proyecto de reforma Constitucional el siguiente texto que, a nuestro parecer, debiera agregarse a continuación del punto final del inciso $2^{\circ}$ del artículo 20:

"Procederá igualmente el recurso de protección respecto de aquellos derechos sociales, económicos o culturales que se satisfacen con prestaciones económicas o de servicio del Estado, o de entidades privadas que operan bajo su control, cuando tales derechos hayan sido afectados por actos u omisiones ilegales".

10. Por lo que respecta a los derechos sociales no prestacionales, alguno de ellos ya están bajo el amparo del recurso de protección, tales como, el derecho de sindicalización, el derecho de libre afiliación y desafiliación a una organización sindical, el derecho a la libertad de trabajo y a la libre elección del trabajo, el derecho a la libre contratación, el derecho a no ser obligado a afiliarse a una organización o entidad como requisito para desarrollar una actividad o trabajo, y el derecho a la libre elección del sistema de salud. Falta aún extender sin embargo el ámbito de aplicación del RP a otros derechos sociales no prestacionales de evidente importancia, como el derecho a la negociación colectiva y el derecho a huelga. Al parecer, tratándose de los derechos no prestacionales, el problema es relativamente más simple que el que plantean los derechos sociales prestacionales, pues bastaría incluirlos en la enumeración del artículo 20, para dejarlos así dentro del ámbito de acción del recurso. Tal vez su exclusión pudo justificarse en una época de gran efervescencia e inestabilidad política y social, pero hoy, en que la igualdad de oportunidades y el sentido de participación social parecen haberse instalado definitivamente en la agenda pública, convendría asegurarles una protección más efectiva. 
